present, IL-1ra levels were in the intermediate range $(\mathrm{n}=42$; mean: $626 \mathrm{pg} / \mathrm{ml}$ ).

Conclusion IL-1ra deficiency appears to predispose patients to a more aggressive disease course of rheumatoid arthritis, whereas in other patients synovial IL-1ra production in response to increased IL-1 activity represents a physiological mechanism to restore the balance between pro-inflammatory and anti-inflammatory activity.

\section{THU0213 THE IMPORTANCE OF SCREENING AND SPINAL INSTRUMENTATION IN PATIENTS WITH INSTABILITY OF UPPER CERVICAL SPINE DUE TO RHEUMATOID ARTHRITIS}

${ }^{1} \mathrm{Z}$ Klezl, ${ }^{2} \mathrm{M}$ Vesela, ${ }^{1} \mathrm{~J}$ Fousek, ${ }^{2} \mathrm{~K}$ Pavelka. 'Department of Orthopedics and Traumatology, Central Military Hospital; ${ }^{2}$ Rheumatology Institute, Prague, Czech Republic

10.1136/annrheumdis-2001.1115

Background Instability of cervical spine is one of the most challenging fields in patients with rheumatoid arthritis (RA). Although most of the patients can be treated conservatively, some experience intractable pain with pronounced neurological symptoms. Sudden death has been reported in $10 \%$ of cases.

Objectives Aim of this study was to determine the importance of screening of patients with RA and cervical spine instrumentation, which restores spinal stability before onset of cervical myelopathy.

Methods We retrospectively evaluated 17 patients surgically treated for instability of the upper cervical spine during 1996 2001. Average age was 53.2 years $(22-72)$, average duration of the disease was 14 years $(3-24), 16$ patients were women. There were 4 patients with cranial settling combined with atlanto-axial or/and subaxial instability and 13 with atlanto-axial instability; one of these patients had associated lateral atlantoaxial instability. Screening included electrophysiological examination, dynamic x-rays, in cases of significant instability MRI is performed in order to determine possible compression of the dural sac by pannus as described by Dvorak. The indications for surgery are: growing neurological deficit or pain, cranial settling, lateral subluxation of $\mathrm{C} 1-\mathrm{C} 2$ more than $2 \mathrm{~mm}$ and retrodental interval in patients with atlanto-axial subluxation $14 \mathrm{~mm}$ or less. Four different instrumentations were used, Ransford loop with sublaminar wires and cables, transarticular screws with wire loop, double sublaminar loop (Brooks) and Cervifix. All patients were using soft collar postoperatively, the one with Brooks procedure was placed into halo-vest for 6 weeks.

Results Patients were evaluated using functional rating score and the Visual Analogue Scale with the mean follow up 14.3 months (6ロ46). Marked improvement was found in both evaluations.

Complications included cerebrospinal fluid leak, which required revision, delayed wound healing, injury to vertebral artery and delayed union of spinal fusion. Although they required longer hospital stay, they were not clinically significant. Conclusion Our results support the need for careful screening of patients with RA, which reveals instability associated with early neurological signs. Indication for surgery should be done before the onset of cervical myelopathy. Internal fixation with Cervifix, Ransford loop and transarticular fixation according to Magerl were satisfactory in maintaining stability of the upper cervical spine before healing of the fusion. Stability of the Brooks procedure was not satisfactory and therefore the patient had to be placed into halo-vest orthosis.

\section{Rheumatoid Arthritis - Treatment}

\section{AB0055 SULPHASALAZINE IN THE TREATMENT OF RHEUMATOID ARTHRITIS: A 2 YEAR PROSPECTIVE STUDY}

${ }^{1} \mathrm{~J}$ Morovic-Vergles, ${ }^{2} \mathrm{~K}$ Berdnik-Gortan, ${ }^{1} \mathrm{D}$ Soldo-Juresa. ${ }^{1}$ Department of Clinical Immunology and Rheumatology; ${ }^{2}$ Rheumatic Service, Institute of Rheumatic Disease "Dr. Drago Ėop", Zagreb, Croatia

10.1136/annrheumdis-2001.1116

Background Sulphasalazine has been suggested as a less effective drug than some of the other disease modifying antirheumatic drugs (DMARDs). It is more suitable for use in milder disease. Sulphasalazine is often the most common first-choice DMARDs because of its good tolerability.

Objectives The aim was to determine the efficacy and tolerability of long-term sulphasalazine treatment of rheumatoid arthritis (RA).

Methods This study examines the response to sulphasalazine $(2,0-3,0 \mathrm{~g}$ daily) over a 2 year period in 40 consecutive patients with severe, active RA. This was defined as seropositiva, erosive RA and persistent activity. Clinical evaluation were performed by the same physician every 3 months and also blood count, erythrocyte sedimentation rate (ESR), serum creatinine, liver blood test and urine were obtained.

Results 40 patients were enrolled in the study. Their mean age at entry to trial was $51,2 \pm 11,6$ years with a mean duration of disease activity of 4 years. After 3 months of the treatment 21 patients showed no significant clinical improvement. A good clinical response was shown by the improvement of the pain, as well as the reduction of the morning stiffness. Reduction in the acute phase response was shown by improvement in the ESR and C-reactive protein (CRP). Of the 40 patients enrolled in the study, 27 showed highest improvement in swollen joints $(p<$ $0,01)$, in the duration of morning stiffness $(\mathrm{p}<0,01)$, ESR $(\mathrm{p}<$ $0,05)$, CRP $(\mathrm{p}<0,05)$ after 6 months compared to pretreatment valves. 2 patients were excluded from study because of an leukopenia, and gastrointestine disturbances and in 2 the drug was ineffective.

Conclusion This study confirmed that sulphasalazine is well tolerated and suggests that patients with severe and active RA could achieve good clinical response to sulphasalazine.

\section{AB0056 THE TIMING OF LOW DOSE GLUCOCORTICOID THERAPY ADMINISTRATION IN TREATMENT OF RHEUMATOID ARTHRITIS}

S Karatay, K Senel, M Ugur, K Yýldýrým. Physical Therapy and Rehabilitation, Atatürk University Medical Faculty, Erzurum, Turkey

10.1136/annrheumdis-2001.1117

\section{Background}

Objectives This study was performed to determine the effects of low dose prednisolone in treatment of rheumatoid arthritis (RA), administered in the morning or at night.

Methods Thirty patients with active RA are divided randomly into two groups. For 6 months, a dosage of $7.5 \mathrm{mg} /$ day prednisolone was administered at 02:00 am or 07:30 am to group I and group II respectively. In both groups, evaluations are performed between 07:30 - 08:00 am. During the treatment, changes observed each month in clinical and laboratory status of 